\title{
TÜRKİYE İLE SEÇİLMİŞ ÜLKELER ARASINDA TARIMSAL KATMA DEĞER YAKINSAMASI: DOĞRUSAL VE DOĞRUSAL OLMAYAN BİRIM KÖK TESTLERİ
}

\author{
Convergence of Agricultural Added Value Between \\ Turkey and Selected Countries: Linear and Nonlinear Unit \\ Root Tests
}

Levent KAYA*

Geliş: 13.05.2020/ Kabul: 01.12.2020

DOI: 10.33399/biibfad.736598

Öz

Tarım sektörü hem gelişmekte olan ülkeler hem de gelişmiş ülkeler için halen çok büyük bir önem arz etmektedir. Küreselleşen dünyada tarım sektöründe rekabet edebilmek için katma değeri yüksek ürünler üretilmesi ve pazarlanması ülkelerin tarım politikalarını belirlemede en önemli etkenlerden biridir. Her alanda olduğu gibi tarımsal alanda da yenilikçi fikirler üretmek ve teknolojiden faydalanmak ülkelere katma değer üretmede büyük bir avantaj sağlamaktadır. Türkiye, tarımsal üretimde dünyada önemli bir yere sahiptir. Türkiye'nin tarımsal katma değer üretmedeki rekabet gücünü ölçmek amacıyla bu çalışmada seçili bazı ülkeler (Çin, Amerika Birleşik Devletleri, Hindistan, Brezilya ve Endonezya) ile Türkiye'nin tarımsal katma değer açısından yakınsama gösterip göstermediği incelenmiştir. Serilere doğrusal olup olmamasına göre farklı birim kök testleri uygulanmıştır. Doğrusal seriler için Fourier KPSS birim kök testi, doğrusal olmayan seriler için Sollis birim kök testi kullanılmıştır. Birim kök testi sonuçlarına göre Türkiye tarımsal katma değerde, Çin ve Amerika Birleşik Devletleri'ne yakınsamaktadır. Brezilya, Hindistan ve Endonezya'ya ise tarımsal katma değer yakınsaması bulunamamıştır.

Anahtar Kelimeler: Tarımsal katma değer, ekonomik büyüme, yakınsama, doğrusallık, birim kök testleri.

JEL Kodları: C01; C22; E01; Q14.

\footnotetext{
* Dr. Öğr. Üyesi, Harran Üniversitesi, İktisadi ve İdari Bilimler Fakültesi, Ekonometri Bölümü, lekaya@harran.edu.tr, ORCID: https:/ / orcid.org/0000-0001-7278-8114
} 


\begin{abstract}
The agricultural sector is still very important for both developing countries and developed countries. The production and marketing of high value added products in order to compete in the agricultural sector in the globalized world is one of the most important factors in determining the agricultural policies of countries. As in all field, produces innovative ideas and benefits from technology provides in the agricultural field gives countries a great advantage in producing added value. Turkey has an important place in the world in agricultural production. In order to measure Turkey's competitiveness in producing agricultural value added, in this study it was investigated some selected countries (China, United States of America, India, Brazil and Indonesia) with Turkey, convergence in terms of agricultural added value. Different unit root tests were applied to the series according to whether they were linear or not. Fourier KPSS unit root test was used for linear series and Sollis unit root test was used for non-linear series. According to the unit root test results, Turkey is converging on China and the United States of America in agricultural added value. Agricultural value added convergence has not been found In Brazil, India and Indonesia.
\end{abstract}

Keywords: Agricultural added value, economic growth, convergence, linearity, unit root tests.

JEL Codes: C01; C22; E01; Q14

\title{
1. Giriş
}

Tarım, özellikle gelişmekte olan ülkelerde kırsal alanda yaşayan insanların geçimini sağladıkları temel sektör olma özelliğini hâlâ korumaktadır. Ayrıca, tarım sektörüne ekonomik kalkınma sürecinde önemli işlevler yüklenmektedir. Bu işlevler; beslenme için gerekli gıda maddeleri üretiminin temin edilmesi, sinai ürünlere talep yaratılması, sınai üretim yapabilmek için gerekli hammadde, sermaye ve emeğin sağlanması ve ekonominin döviz gereksiniminin giderilmesi olarak sıralanabilir. Bütün bu işlevlerinden dolayı, tarım, dünyanın hemen her yerinde özel önem verilen bir sektördür (Doğan, 2009:366).

Tarım sektörü genellikle ekonomik sistemlerin ayrılmaz bir parçasını oluşturmaktadır. Tarım sektörünün ülke ekonomisi içerisindeki yeri, tarımın genel ekonomi içerisinde yaratmış olduğu katma değer ile ölçülmektedir. Bu katma değer ise, tarımsal faaliyetler 
sonucu ortaya çıkan hâsıla, tarımsal çıktı, dış ticaret, istihdam ve diğer sektörlere girdi temini gibi başlıklardan oluşmaktadır (Doğan vd., 2015:34).

Tarımsal katma değer kısaca tarımsal ürünün fiziksel görünümünde ve maddi değerinde bir iyileşme meydana getirmek şeklinde tanımlanabilir. Katma değerli tarım hem tarımsal girişimcilik hem de kırsal kalkınma için önemli bir stratejidir (Lu ve Dudensing, 2015:2).

Tarımda katma değer artışı, kırsal istihdam oranının arttırılmasında, tarımla uğraşan kesimin ekonomik altyapısının çeşitlendirilmesinde, tarımsal üretimin teşvik edilmesinde, tarımla uğraşan nüfusun gelir düzeyinin arttırılmasında ve finansal istikrarın sağlanmasında önemli rol oynamaktadır (Akyol, 2018:228).

Mevcut katma değerli tarım ve kırsal tartışmaların çoğu iki genel kategoriye odaklanır. Birincisi daha yüksek kalite, daha iyi beslenme veya daha fazla kolaylık sunan katma değerli gıda ürünleri, ikincisi ise tahillar, yağlı tohumlar veya geleneksel olmayan bitkilerden elde edilen endüstriyel, gıda dışı katma değerli ürünlerdir (Cowan, 2002:28).

Çalışmanın ilk bölümünde yakınsama hipotezi ile ilgili temel bilgiler verilmiştir. İkinci bölümde, konuyla ilgili literatür çalışmalarına yer verilmiştir. Üçüncü bölümde ise tarımsal katma değerde ön plana çıkan ülkelere Türkiye'nin yakınsama gösterip göstermediği analiz edilmiştir.

\section{Yakınsama Hipotezi}

Ekonomiler arasındaki gelir eşitsizliğinin zaman içinde daralmasını beklemeli miyiz? Düşük gelirli ekonomilerin yüksek gelirli ekonomilerden daha hızlı büyüme eğilimi var mı? Yüksek gelirli ekonomilerde ekonomik büyüme eninde sonunda yavaşlayacak mı? Yukarıdaki soruların cevapları, uluslararası ticaretin yokluğunda bile olumlu olabilir mi? Yüksek gelirli bir ekonomideki büyüme, düşük gelirli bir ekonomide daha yüksek bir büyüme oranına neden olur mu veya aksi durum mümkün olabilir mi? Başka bir deyişle, ekonomik büyümede uluslararası bir dışsallık var mı? Yukarıdaki sorularla 
ilgilenen yakınsama hipotezi, özellikle 1980'lerin ortalarından bu yana büyük bir literatür üreten birçok ekonomistin dikkatini çekmiştir. Ancak fikir, ekonomideki en eski tartışmalardan birini temsil eder (Rassekh, 1998:85).

Yakınsama hipotezi Solow büyüme modeline dayanmaktadır, buna göre, eğer farklı ülkeler ayn tercihlere ve teknolojiye sahipse, biriken faktörlerin, özellikle de sermayenin kullanımında azalan marjinal getirilerin varlığı göz önüne alındığında, fakir ülkeler zengin ülkelerden daha hızlı büyüme eğilimindedir (Rivas vd., 2017:2). Yakınsama hipotezi başlangıçta ekonomik büyüme literatüründe yaygın olarak kullanılmış olsa da, ilerleyen süreçlerde birçok makroekonomik değişkenin davranışını ortaya koymak amacıyla da kullanılır olmuştur (Yazgan vd., 2018:122). Dolayısıyla yakınsama hipotezinin modern makroekonomik teori üzerinde önemli etkileri vardir (Ain ve Zulfiqar, 2018:126).

Yakınsama analizlerinde zaman serisi yaklaşımının kullanılmaya başlanmasıyla birlikte yakınsamanın, deterministik ve stokastik tanımlaması yapılmıştır (Ceylan, 2010a:57). Deterministik yakınsama, nispi değişkenin logaritmasının düzeyde durağanlığını ifade ederken stokastik yakınsama değişkenin grup ortalamasına oranının logaritmasının düzeyde durağanlığını ifade etmektedir (Esenyel, 2017:43). Zaman serisi tekniği hem ülkeler arası yakınsama araştırmasında ve hem de ülke içi yakınsama araştırmasında kullanılabilmesi bakımından avantajlıdır. Ayrıca zaman serisi tekniği örneklem içi hareketliliği de ortaya koymaktadır. Zaman serisi tekniğinde ele alınan serilerin durağan olması durumunda, yakınsama çıkarımı yapılmaktadır (Ceylan, 2010b:313). Buna göre yakınsaması incelenen gelir veya harcama gibi bir değişken, birim kök içermiyorsa bu durumda ele alınan değişkendeki şoklar geçici bir etkiye sahip olacak ve yakınsama gerçekleşecektir. Ancak değişkenin birim kök içermesi durumunda şoklar kalıcı etkiye sahip olarak ele alınan değişkendeki eşitsizlikleri artıracak, diğer bir ifade ile rraksamaya neden olacaktır (Akarsu vd., 2019:92). 


\section{Türkiye'de Tarımsal Katma Değer}

Türkiye'de tarım sektörünün GSYİH içerisindeki payı 2018 yılı için $\% 5.82$ 'dir. Kırsal kesimde yaşayan nüfusun toplam nüfus içerisindeki payı \%24.86'dır. 2018 yılı için tarımsal katma değer 44.87 milyar dolar olarak gerçekleşmiştir. Tablo 1'de bu çalışmada yer alan ülkelere ve Türkiye'ye ait yıllık tarımsal katma değer verileri gösterilmiştir.

Tablo 1: Seçili Ülkelerde Yıllık Tarımsal Katma Değer (Milyar Dolar)

\begin{tabular}{|l|c|c|c|c|c|}
\hline \multicolumn{1}{|c|}{ Ülkeler } & $\mathbf{2 0 1 3}$ & $\mathbf{2 0 1 4}$ & $\mathbf{2 0 1 5}$ & $\mathbf{2 0 1 6}$ & $\mathbf{2 0 1 7}$ \\
\hline Çin & 855.87 & 905.46 & 927.73 & 905.10 & 918.79 \\
\hline Hindistan & 318.40 & 342.41 & 340.24 & 372.19 & 414.27 \\
\hline Brezilya & 111.45 & 106.24 & 77.84 & 87.89 & 95.18 \\
\hline Endonezya & 121.88 & 118.81 & 116.15 & 125.61 & 133.57 \\
\hline Amerika Birleşik Devletleri & 223.83 & 208.27 & 189.95 & 175.92 & 178.58 \\
\hline Türkiye & 63.93 & 61.56 & 59.36 & 53.41 & 51.86 \\
\hline
\end{tabular}

Kaynak: https://databank.worldbank.org/source/world-development-indicators

Şekil 1: Ülkelere Ait Yıllık Tarımsal Katma Değer Grafikleri
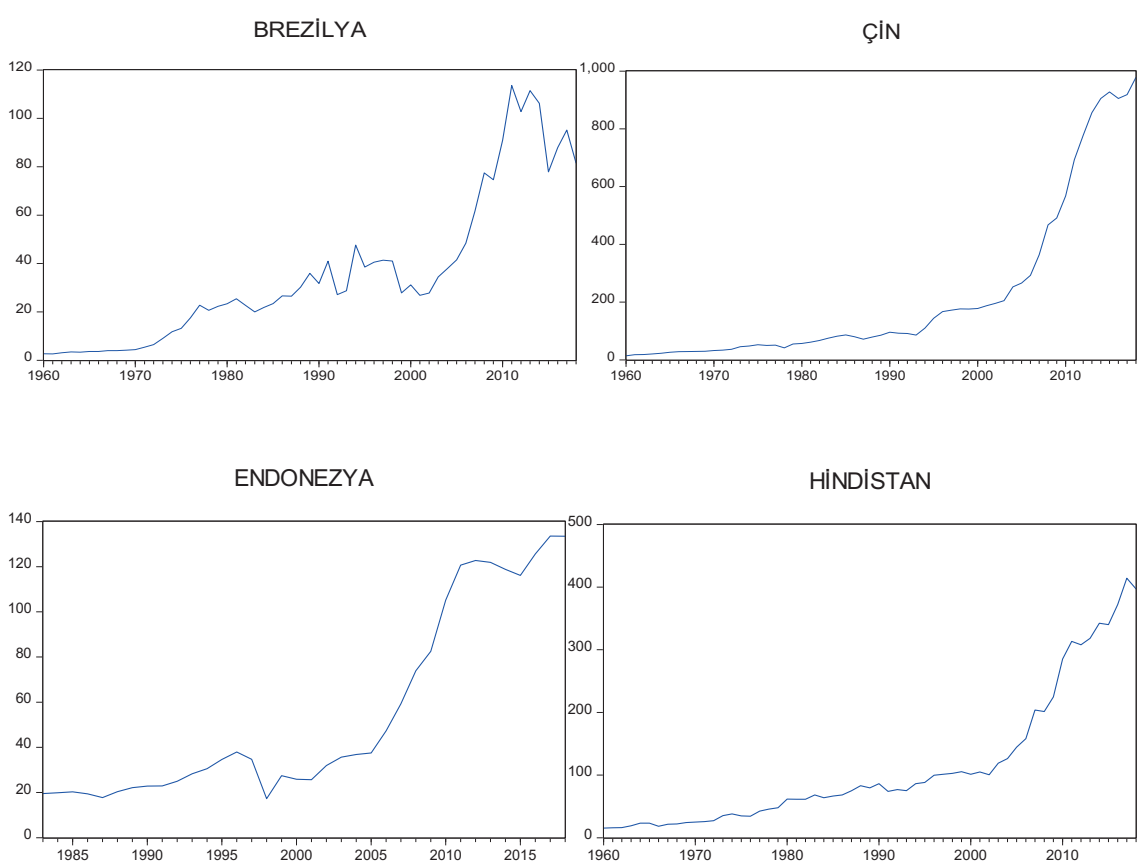


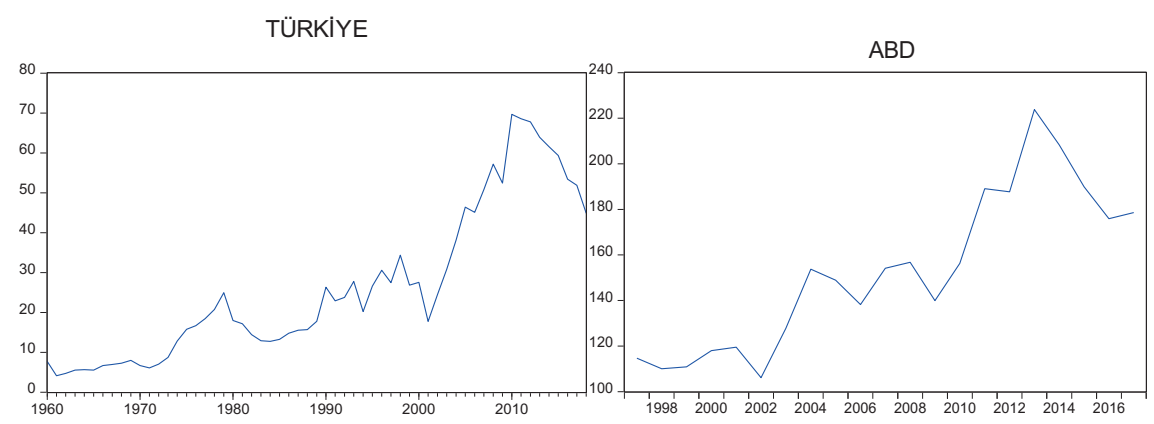

\section{Literatür Taramas1}

Literatürde tarımsal gelir ve tarımsal katma değerin ekonomik büyümeyle ilişkisini inceleyen birçok çalışma mevcuttur. Gerek Türkiye gerekse birçok yabancı ülke(ler) için yapılan mevcut çalışmaların tamamında farklı ekonometrik yöntemler kullanılarak anlamlı ilişkiler elde edilmiştir.

Aktaş vd., (2015), seçilmiş ülkelerle yaptıkları panel veri analizi ile pazar fiyat desteği ve girdi desteğinin tarımsal çıktıyı arttırdığı sonucuna ulaşmışlardır.

Akyol (2018), seçilmiş ülkelerle yaptığı panel veri analizi ile tarımsal teşviklerdeki artış ile tarımsal katma değer arasında pozitif bir ilişki olduğu sonucuna ulaşmışlardır.

Ceylan ve Özkan (2013), Avrupa Birliği Ülkeleri için yaptıkları panel veri analizi ile kişi başına gelirin tarımsal katma değer esnekliğini 0.025 olarak bulmuşlardır. Ayrıca AB ülkelerinde ortalama kişi başına gelirin üye olmayanlara göre daha yüksek olduğunu göstermişlerdir.

Doğan vd., (2019), Türkiye'de seçili iller için yaptıkları panel eşbütünleşme analizi ile tarımsal GSYİH ile tarımsal krediler arasındaki ilişkiyi incelemişlerdir. Değişkenler arasında uzun vadeli eşbütünleşme ilişkisi bulmuşlardır. Ayrıca kentsel ve kırsal bölgelerdeki değişkenler arasında iki yönlü nedensellik tespit etmişlerdir.

Verter ve Becvarova (2016), Nijerya için yaptıkları regresyon analizi ve Granger nedensellik analizi ile Nijerya'da tarımsal ihracatın 
ekonomik büyüme üzerine etkisini araştırmışlardır. Analizler sonucunda tarımsal ihracatın ekonomik büyümeye neden olduğunu göstermişlerdir.

Şimşir (2012), Türkiye için yaptığı regresyon analizi sonucunda tarımsal kredilerin, tarımsal gelir ve istihdam üzerinde doğrudan bir etkiye sahip olduklarını göstermiştir.

Ali vd., (2013), Pakistan için yaptıkları Johansen eşbütünleşme analizi ile tarımsal katma değer ve hizmet sektörü katma değerinin gelir eşitsizliğini uzun vadede etkilediği sonucuna varmışlardır.

Shah vd., (2015), Pakistan için yaptıkları Johansen eşbütünleşme analizi ile tarımsal ihracatın Pakistan'ın ekonomik büyümesi ile negatif, tarım dışı ihracatın ekonomik büyüme ile pozitif bir ilişkisi olduğunu göstermişlerdir.

Alamdarlo (2016), İran için yaptığı panel veri analizi ile Kuznets teorisini kullanarak Doğal kaynaklar ile tarımsal kalkınma arasındaki ilişkiyi incelemiştir ve aralarında doğrudan bir ilişki olduğunu tespit etmiştir.

Soyyiğit ve Yavuzaslan (2019), E7 ülkeleri ile yaptıkları nedensellik analizi ile hükümet etkinliği endeksinin hem ekonomik karmaşıklık endeksini hem de tarımsal katma değeri etkilediğini ve ayrıca tarımsal katma değerden hükümet etkinliği endeksine bir nedensellik olduğunu bulmuşlardır.

Bashir vd., (2018), Endonezya için yaptıkları Johansen eşbütünleşme analizi ile insan sermayesi, ekonomik büyüme, hükümet harcamaları, kırsal nüfus ve teknolojinin tarımsal katma değer üzerinde olumlu ve anlamlı bir etkiye sahip olduğunu göstermişlerdir.

\section{Ekonometrik Model}

Bu çalışmada Türkiye' ye nazaran daha yüksek bir tarımsal katma değere sahip olan ülkeler (Çin, Hindistan, Brezilya, Endonezya ve Amerika Birleşik Devletleri) seçilmiş ve Türkiye'nin bu ülkelere tarımsal katma değerde yakınsayıp yakınsamadığı araştırılmıştır. Çalışmada yıllık verilerle çalışılmıştır. Veriler Worldbank resmî 
sitesinden elde edilmiştir. Türkiye, Brezilya, Çin ve Brezilya için 1960 -2018, Endonezya için 1983-2018, Amerika Birleşik Devletleri için 1997-2017 zaman aralığı kullanılmıştır. Serinin durağan olması yakınsamanın gerçekleştiğini, birim köklü olması ise yakınsamanın gerçekleşmediğini göstermektedir. Tarımsal katma değer yakınsaması için seriler aşağıdaki gibi dönüştürülmüştür.

$$
y_{i t}=\ln \frac{T K D_{t, \text { Türkiye }}}{T K D_{i t}}
$$

(1) nolu denklemde $T K D_{t, \text { Türkiye }}$, Türkiye'ye ait yıllık tarımsal katma değer, $T K D_{i t}$, i. ülkeye ve t. zamana ait tarımsal katma değer, ln ise doğal logaritmayı ifade etmektedir.

\subsection{Doğrusallık Testi}

Literatürde serilerin doğrusallığını sınayan çok sayıda test bulunsa da bu testler genellikle doğrusallığı incelenen serinin durağan olduğu varsayımından hareket ederler. Dolayısıyla düzey değerinde durağan olmayan serilere bu testleri uygulamak elde edilen sonuçların hatalı olmasına neden olabilir (Yılancı ve Tıraşoğlu, 2016:5). Harvey ve Leybourne (2007) ve Harvey vd., (2008) doğrusallık testleri diğer yöntemlerden farklı olarak serilerin durağanlık varsayımını göz ardı eder. Harvey vd. (2008), Harvey ve Leybourne (2007)'ye göre daha iyi sonlu örneklem boyut ve güç özelliklerine sahiptir.

Harvey ve Leybourne (2007), Taylor açılımını kullanarak I(0) ve I(1) süreçlerini dikkate alan aşağıdaki denklemi kullanmışlardır.

$$
y_{t}=\beta_{0}+\beta_{1} y_{t-1}+\beta_{2} y_{t-1}^{2}+\beta_{3} y_{t-1}^{3}+\beta_{4} \Delta y_{t-1}+\beta_{5}\left(\Delta y_{t-1}\right)^{2}+\beta_{6}\left(\Delta y_{t-1}\right)^{3}+\varepsilon_{t}
$$

(2) nolu denkleme göre temel hipotez;

$$
H_{0}: \beta_{2}, \beta_{3}, \beta_{5}, \beta_{6}=0
$$

Alternatif hipotez ise;

$H_{1}$ : en az bir parametre $\beta_{2}, \beta_{3}, \beta_{5}, \beta_{6} \neq 0$ 
Temel hipotez doğrusallığı, alternatif hipotez ise doğrusal olmamayı ifade etmektedir. Test istatistiği olarak da (3) nolu eşitliği önermişlerdir.

$$
W_{T}=\frac{R S S_{1}-R S S_{0}}{R S S_{0} / T}
$$

$\mathrm{RSS}_{1}$, I(1) süreci için hata terimi kareler toplamını, RSS 0 , I(0) süreci için hata terimi kareler toplamını, $\mathrm{T}$ ise gözlem sayısını ifade etmektedir. Harvey ve Leybourne (2007) test istatistiği, $\chi_{4}^{2}$ dağılımına uygunluk göstermektedir.

Harvey vd., (2008) testi için durağan olma I(0) ve durağan olmama I(1) varsayımı altında kullanılacak modeller sırasıyla aşağıdaki gibidir.

$$
\begin{aligned}
& y_{t}=\beta_{0}+\beta_{1} y_{t-1}+\beta_{2} y_{t-1}^{2}+\beta_{3} y_{t-1}^{3}+\varepsilon_{t} \\
& \Delta y_{t}=\lambda_{1} \Delta y_{t-1}+\lambda_{2}\left(\Delta y_{t-1}\right)^{2}+\lambda_{3}\left(\Delta y_{t-1}\right)^{3}+\varepsilon_{t}
\end{aligned}
$$

I(0) için hipotezler;

$$
H_{0, I(0)}: \beta_{2}=\beta_{3}=0 \quad \text { (Doğrusal) }
$$

$H_{1, I(0)}$ :en az bir parametre $\beta_{2}, \beta_{3}, \beta_{5}, \beta_{6} \neq 0 \quad$ (Doğrusal değil)

I(1) için hipotezler;

$$
\begin{aligned}
& H_{0, I(1)}: \lambda_{2}=\lambda_{3}=0 \quad \text { (Doğrusal) } \\
& H_{1, I(1)}: \lambda_{2} \neq 0 \text { ve/veya } \lambda_{3} \neq 0 \quad \text { (Doğrusal değil) }
\end{aligned}
$$

Harvey vd., (2008) için test istatistiği;

$$
W_{\lambda}=\{1-\lambda\} W_{0}+\lambda W_{1}
$$

şeklinde bulunur. (6) nolu eşitlikte $W_{0}, \mathrm{I}(0)$ varsayımı altında hesaplanan test istatistiği, $W_{1}$ ise I(1) varsayımı altında hesaplanan test istatistiğidir. $W_{\lambda}$ test istatistiği, $\chi_{2}^{2}$ dağılımına uygunluk göstermektedir. 


\subsection{Doğrusal Birim Kök Testi}

Çalışmada doğrusal seriler için durağanlık analizi Fourier fonksiyonu ile geliştirilen, KPSS testi ile yapılacaktır (Becker vd., 2006). Fourier fonksiyonu ile geliştirdikleri Fourier KPSS birim kök testini literatüre kazandırmışlardır. Testin, diğer birim kök testlerine karşı en önemli üstünlüğü yapısal kırılmaları analize dahil etmesidir. Fourier KPSS testinin en önemli avantajı serilerdeki kırılmaların yerlerinin, sayısının ve formunun önceden tespit edilmesine gerek olmamasıdır (Alper ve Demiral, 2017: 208). Bu testte bilinmeyen doğrusal dişı durumları saptamak üzere trigonometrik terimler kullanılmakta, birim köklü sıfır hipotezinin durağan serilerde gücünün düştüğü vurgusu yapılarak KPSS tipi durağanlık testi önerilmektedir (Tekin, 2018: 115).

Fourier KPSS (FKPSS) durağanlık testi ani değişimlerin yanında yavaş değişimleri de tespit edebilmektedir. Testin gücü, yapısal değişimlerin konumundan, sayısından ve biçiminden etkilenmemektedir (Yilanc1, 2017: 56).

$$
\begin{aligned}
& y_{t}=\alpha+\gamma_{1} \sin \left(\frac{2 \pi k t}{T}\right)+\gamma_{2} \cos \left(\frac{2 \pi k t}{T}\right)+e_{t} \\
& y_{t}=\alpha+\beta t+\gamma_{1} \sin \left(\frac{2 \pi k t}{T}\right)+\gamma_{2} \cos \left(\frac{2 \pi k t}{T}\right)+e_{t}
\end{aligned}
$$

(7) nolu model düzey durağanlık temel hipotezini, (8) nolu model ise trend durağanlık temel hipotezini sınamak için kullanılır. Yukarıdaki modellerde $t$, trend değerini, $k$ frekans değerini, $T$, gözlem sayısını, sin ve cos ise trigonometrik terimleri ifade etmektedir.

Fourier KPSS için test istatistiği;

$\tau_{\mu}(k)$ ya da $\tau_{\tau}(k)=\frac{1}{T^{2}} \frac{\sum_{t=1}^{T} \xi_{t}(k)^{2}}{8_{0}^{2}}$

şeklinde hesaplanır. (9) nolu eşitlikte, 


$$
\mathcal{S}^{\prime}(k)=\sum_{j=1}^{t} \mathbb{e} \rho
$$

(10) nolu eşitlikteki \&o, (7) veya (8) nolu denklemden elde edilen en küçük kareler kalıntılarıdır. Uzun dönem varyansın parametrik olmayan bir tahmini olan $\xi_{0}^{2}, l$ gecikme ve $w_{j}$ ăgırlı seviyelerinin seçilmesiyle aşağıdaki denklem elde edilir.

$$
8_{0}^{2}=g / \rho+2 \sum w_{j} \%
$$

(11) numaralı eşitlikte $9 / 0$, (7) veya (8) numaralı modelden elde edilen $\&_{t}{ }^{\prime}$ 'nin $j$ inci örneklem otokovaryansıdır. Temel hipotez serinin durağan olduğunu alternatif hipotez ise birim köklü olduğunu ifade etmektedir.

Trigonometrik terimlerin anlamlılı̆̆ını sınamak için kullanılacak test istatistiği;

$$
F_{i}(k)=\frac{\left(S S R_{0}-S S R_{1}(k)\right) / 2}{S S R_{1}(k) /(T-q)}
$$

ile elde edilir. (12) nolu denklemde $\operatorname{SSR}_{1}(k)$, (7) veya (8) nolu modelden elde edilen kalıntı kareler toplaminı, $S S R_{0}$, trigonometrik terimsiz modelden elde edilen kalıntı kareler toplamını ifade etmektedir. $T$, gözlem sayısını $q$ ise bağımsız değişken sayısını ifade etmektedir. Temel hipotez trigonometrik terimlerin anlaml olmadığını ifade etmektedir. Trigonometrik terimlerin anlamlı olmaması durumunda fourier KPSS testi yerine standart KPSS testinin kullanilması daha uygun olacaktır.

\subsection{Doğrusal Olmayan Birim Kök Testi}

Sollis (2009), ESTAR sürecine dayanarak asimetrik etkileri dikkate alan ve böylece serinin orijin etrafında simetrik olması gerektiği varsayımını yumuşatarak yeni bir test prosedürü ileri sürmüştür. Bu testin en önemli avantajı hem simetrik ve hem de asimetrik doğrusal olmayan etkileri dikkate almasıdır (Yazgan vd., 2018: 124). Sollis (2009) tarafından geliştirilen test hem üstel fonksiyonu hem de lojistik fonksiyonu kullanmaktadır (Güriş vd., 2017: 39). 


$$
\begin{array}{lc}
\Delta y_{t}=G_{t}\left(\gamma_{1}, y_{t-1}\right)\left\{S_{t}\left(\gamma_{2}, y_{t-1}\right) \rho_{1}+\left(1-S_{t}\left(\gamma_{2}, y_{t-1}\right)\right) \rho_{2}\right\} y_{t-1}+\varepsilon_{t} \\
G_{t}\left(\gamma_{1}, y_{t-1}\right)=1-\exp \left(-\gamma_{1}\left(y_{t-1}^{2}\right)\right) & \gamma_{1} \geq 0 \\
S_{t}\left(\gamma_{2}, y_{t-1}\right)=\left[1+\exp \left(-\gamma_{2} y_{t-1}\right]^{-1}\right. & \gamma_{2} \geq 0
\end{array}
$$

(13) nolu modelde $\varepsilon_{t}$, iid $\left(0, \sigma^{2}\right)$ özelliği göstermektedir. (13) nolu denklemin genişletilmiş hali aşağıda gösterildiği gibidir.

$$
\Delta y_{t}=G_{t}\left(\gamma_{1}, y_{t-1}\right)\left\{S_{t}\left(\gamma_{2}, y_{t-1}\right) \rho_{1}+\left(1-S_{t}\left(\gamma_{2}, y_{t-1}\right)\right) \rho_{2}\right\} y_{t-1}+\sum_{i=1}^{k} \kappa_{i} \Delta y_{t-i}+\varepsilon_{t}
$$

Sollis (2009), aşağıda belirtilen modelde görüldüğü gibi lojistik fonksiyonu dikkate alan Taylor açılımını kullanmaktadır.

$$
\Delta y_{t}=\phi_{1} y_{t-1}^{3}+\phi_{2} y_{t-1}^{4}+\eta_{t}
$$

(17) numaralı denklemin genişletilmiş hali aşağıda gösterildiği gibidir.

$$
\Delta y_{t}=\phi_{1} y_{t-1}^{3}+\phi_{2} y_{t-1}^{4}+\sum_{i=1}^{k} \kappa_{i} \Delta y_{t-i}+\eta_{t}
$$

Temel hipotez; $\mathrm{H}_{o}: \phi_{1}=\phi_{2}=0$ şeklinde kurulur. Temel hipotezin reddedilmesi kullanılan serilerin durağan olduğu anlamına gelir. Bu denklem, ham seri (raw data), ortalamadan çıarılmış seri (demeaned) ve trendden arındırılmış (de-trended) seri için kullanılabilir (Yazgan vd., 2018: 125).

Sollis (2009) testi için F test istatistiği aşağıdaki gibidir.

$$
F=(R \hat{\beta}-r)^{\prime}\left[\hat{\sigma}^{2} R\left\{\sum_{t} x_{t} x_{t}^{\prime}\right\}^{-1} R^{\prime}\right]^{-1}(R \hat{\beta}-r) / m
$$

F test istatistiği için kritik değerler Sollis (2009) çalışmasında yer almaktadır. Sollis (2009) F testinin kritik değerlerini (raw data), (demeaned) ve (de-trended) olmak üzere üç durum için tablolaştırmıştır. 


\section{Araştırma Bulguları}

\subsection{Doğrusallık Analizi}

Tablo 2: Doğrusallık Test Sonuçları

\begin{tabular}{|c|c|c|c|c|}
\hline \multirow[t]{2}{*}{ Ülkeler } & \multicolumn{3}{|c|}{ Harvey ve Leybourne (2007) } & \multirow[t]{2}{*}{ Harvey vd., (2008) } \\
\hline & $\% 1$ & $\% 5$ & $\% 10$ & \\
\hline Çin & 4.90 & 4.82 & 4.78 & $16.06^{* * *}$ \\
\hline Hindistan & 7.90 & 7.79 & 7.72 & 3.54 \\
\hline Endonezya & 8.67 & 8.56 & $8.50^{*}$ & $9.63^{* * *}$ \\
\hline Brezilya & 6.57 & 6.49 & 6.45 & 3.04 \\
\hline Amerika Birleşik Devletleri & 5.76 & 5.65 & 5.59 & $4.91^{*}$ \\
\hline
\end{tabular}

Not: Harvey ve Leybourne (2007) \%1, \%5 ve \%10 için kritik değerleri sırasıyla 13.27, 9.48 ve 7.77 'dir. Harvey vd., (2008) \%1, \%5 ve \%10 için kritik değerleri sırasıyla 9.21, 5.99 ve 4.60 'tır. *, ** ve *** sirasiyla $\% 10, \% 5$ ve \%1 için doğrusallık hipotezinin reddedildiğini ifade etmektedir.

Tablo 2'de görüldüğü üzere Harvey ve Leybourne (2007) testine göre Çin, Hindistan, Brezilya ve Amerika Birleşik Devletleri'ne ait test istatistik değerleri kritik değerlerden küçük olduğu için serilerin doğrusal olduğunu ileri süren temel hipotez reddedilememektedir. Endonezya'ya ait seri ise doğrusal yapıda değildir. Harvey vd., (2008) testine göre ise, Çin, Endonezya ve Amerika Birleşik Devletleri'ne ait test istatistikleri kritik değerlerden büyük olduğu için serilerin doğrusal olduğunu ileri süren temel hipotez reddedilmektedir. Hindistan ve Brezilya'ya ait seriler ise doğrusal yapıdadır. Çin ve Amerika Birleşik Devletleri'ne ait veriler doğrusallık testlerinde farklı sonuçlar verdiği için bu ülkelere ait verilere hem doğrusal hem de doğrusal olmayan birim kök testleri uygulanmıştır. 


\subsection{Birim Kök Analizleri}

Tablo 3: Fourier KPSS Birim Kök Testi Sonuçları

\begin{tabular}{|l|c|c|c|c|}
\hline Ülkeler & KKT & $\mathbf{k}$ & Fourier KPSS & F-Stat \\
\hline Brezilya & 7.9350 & 1 & 0.4474 & $15.9607^{* * *}$ \\
\hline Çin & 0.3965 & 1 & 0.2525 & $15.0295^{* * *}$ \\
\hline Hindistan & 0.3279 & 4 & 0.5078 & $10.1395^{* * *}$ \\
\hline $\begin{array}{l}\text { Amerika } \\
\text { Birleşik Devletleri }\end{array}$ & 0.0259 & 1 & 0.0725 & $20.9562^{* * *}$ \\
\hline
\end{tabular}

Not: $\mathrm{k}=1$ için Fourier KPSS kritik değerler \%10, \%5 ve \%1 için sırasıyla 0.1318, 0.1720 ve $0.2699^{\prime}$ dur. $\mathrm{k}=4$ için $0.3476,0.4592$ ve $0.7222^{\prime}$ dir. Trigonometrik terimlerin anlamlılığını test etmek için kullanılan F testi için kritik değerler, \%10, \%5 ve \%1 için sırasıyla $4.133,4.929$ ve 6.730 'dur. Anlamlılık seviyeleri $\% 10, \% 5$ ve $\% 1$ için sırasıyla *, ** ve *** ile gösterilmiştir.

$\mathrm{Bu}$ çalışmada Doğrusal serilere Fourier KPSS birim kök testi uygulanmıştır. Tablo 3'e göre bütün ülkeler için F istatistik değerleri kritik değerlerden büyük olduğu için trigonometrik terimler anlamlı bulunmuştur. Fourier KPSS birim kök testine göre Amerika Birleşik Devletleri serisi durağan, Çin, Hindistan ve Brezilya'ya ait serilerin ise birim köklü olduğu sonucuna ulaşılmıştır. Bu sonuçlara göre tarımsal katma değerde Türkiye; sadece Amerika Birleşik Devletleri'ne yakınsamaktadır.

Şekil 2'de Fourier fonksiyonlarının serilerdeki salınımları iyi bir şekilde yakalayıp tahminde bulunduğunu söyleyebiliriz. 
Şekil 2: Fourier fonksiyonlar

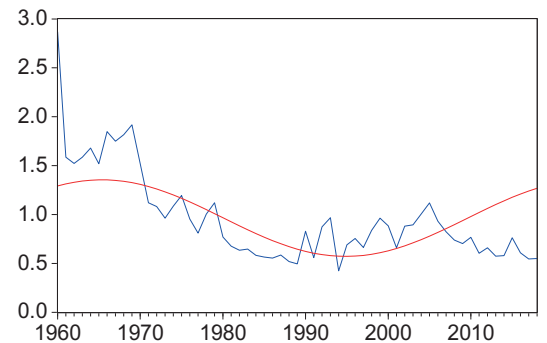

Brezilya

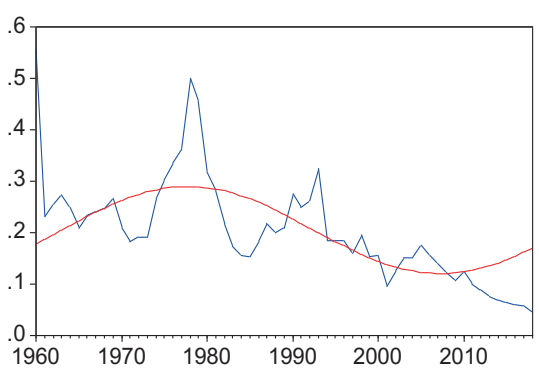

Çin

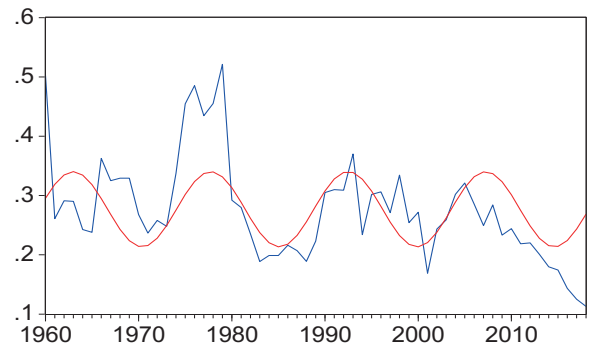

Hindistan

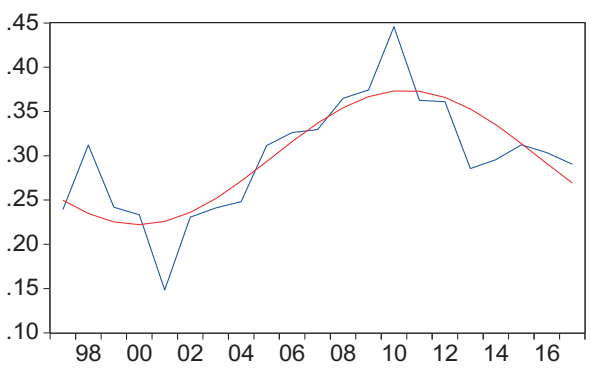

Amerika Birleşik Devletleri

Tablo 4: Sollis (2009) Birim Kök Testi Sonuçları

\begin{tabular}{|l|c|c|c|c|}
\hline Ülkeler & k & Sollis $_{\mathbf{m}}$ & $\mathbf{k}$ & Sollis $_{\boldsymbol{t}}$ \\
\hline Çin & 0 & $29.336^{* * *}$ & 3 & $10.437^{* * *}$ \\
\hline Endonezya & 4 & 1.878 & 4 & 1.835 \\
\hline Amerika Birleşik Devletleri & 2 & $5.189^{* *}$ & 8 & $58.068^{* * *}$ \\
\hline
\end{tabular}

Not: $\mathrm{m}$ indisi ortalamadan arındırılmış, $\mathrm{t}$ indisi trendden arındırılmış modeli temsil etmektedir. Test istatistikleri Sollis (2009) makalesindeki kritik değerler ile karşılaştırılmıştır. *, ** ve *** sırasıyla \%10, \%5 ve \%1 için temel hipotezin reddedildiğini, başka bir deyişle durağan olduğunu ifade etmektedir.

Doğrusal olmayan yapıya sahip serilere Sollis (2009) birim kök testi uygulanmıştır. Tablo 4'e göre hem ortalamadan arındırılmış yapı için hem de trendden arındırılmış yapı için Çin ve Amerika Birleşik Devletleri'ne ait serilerin durağan olduğu sonucuna varılmıştır. Endonezya'ya ait seri ise birim köklü çıkmıştır. Tarımsal katma değerde Türkiye'nin, Çin ve Amerika Birleşik Devletleri'ne yakınsadığı sonucuna ulaşılmıştır. 


\section{Sonuç}

Küresel ekonominin bir sonucu olarak teknolojik gelişmelere ayak uydurabilmek ve uluslararası pazarlarda rekabet edebilme gücüne sahip olmak her sektörde olduğu gibi tarım sektöründe de bir zorunluluk haline gelmiştir. Günümüzde birçok kesim, tarımsal katma değerin tarımsal gelişmişliğin önemli göstergelerinden biri olduğu konusunda hem fikirdir. Türkiye'nin tarımsal katma değerde dünyada önemli bir yere sahip olduğu düşünüldüğünden bu çalışmada tarımsal katma değerde Türkiye'nin öne çıan bazı ülkelere (Çin, Hindistan, Endonezya, Brezilya, Amerika Birleşik Devletleri) yakınsayıp yakınsamadığı araştırılmıştır. İlk aşamada (1) nolu eşitlik kullanılarak veriler dönüştürülmüştür. Dönüştürülen verilere iki farklı doğrusallık testi uygulanmıştır. Brezilya ve Hindistan'a ait seriler her iki test sonucuna göre doğrusal çıkmıştır. Endonezya'ya ait serinin ise doğrusal bir yapıda olmadığı sonucuna ulaşılmıştır. Çin ve Amerika Birleşik Devletleri'ne ait seriler her iki doğrusallık testinde farklı sonuçlar verdiğinden dolayı bu iki ülkeye durağanlık sinamasında hem doğrusal hem de doğrusal olmayan birim kök testi uygulanmıştır. Ülkelere ait dönüştürülmüşs serilerin birim köke sahip olmamaları yakınsamanın gerçekleştiği şeklinde yorumlandığından dolayı serilere doğrusal olup olmama durumuna göre farklı birim kök testleri uygulanmıştır. Doğrusal seriler için trigonometrik fonksiyonları dikkate alan Fourier KPSS testi uygulanmış ve elde edilen sonuçlara göre Türkiye' nin tarımsal katma değerde Amerika Birleşik Devletleri'ne yakınsadığı sonucuna ulaşılmıştır. Doğrusal olmayan seriler için Sollis (2009) birim kök testi sonuçlarına göre Türkiye'nin Çin ve Amerika Birleşik Devletleri'ne yakınsadığı görülmüştür. Genel ifadeyle Türkiye'nin tarımsal katma değerde Çin ve Amerika Birleşik Devletleri'ne yakınsadığı, Brezilya, Hindistan ve Endonezya'ya ise bir yakınsama göstermediği görülmüştür. Elde edilen bu sonuçlar Türkiye gibi gelişmekte olan bir ülkenin tarımsal katma değerde gelişmiş ülkelere yakınsadığını göstermektedir. Tarımsal alanda rekabet gücünü arttırabilecek ve tarımsal katma değerdeki artışın sürekliliğini sağlayacak tarım politikalarının uygulanması Türkiye'nin tarımsal alanda daha iyi yerlere gelmesini sağlayacaktır. 


\section{Kaynakça}

Ain, Q. \& Zulfiqar, K. (2018). An Analysis of income convergence across Asian countries. Forman Journal Of Economic Studies. 14, 125-141.

Akarsu, G.; Cafrı, R. \& Bıdırdı, H. (2019). OECD ülkelerinde sağlık harcamalarının kamu-özel bileşenleri yakınsıyor mu? Doğrusal olmayan panel birim kök testi bulguları. Sosyoekonomi Dergisi. 27(41), 89-112.

Aktaş, E.; Altıok, M. \& Songur, M. (2015). Farklı ülkelerdeki tarımsal destekleme politikalarının tarımsal üretim üzerine etkisinin karşılaştırılmalı analizi. Anadolu Üniversitesi Sosyal Bilimler Dergisi, 15(4), 55-74.

Akyol, M. (2018). Tarımsal teşviklerle katma değer arasındaki ilişkinin incelenmesi: yeni endüstrileşen ülkeler için panel eşanlı denklemler sistemi analizi. The Journal Of International Scientific Researches. 3(3), 226-236.

Alamdarlo, H. N. (2016). Water consumption, agriculture value added and carbon dioxide emission in Iran, environmental kuznets curve hypothesis. International Journal Of Environmental Science and Technology. 13, 2079-2090.

Ali, S.; Mustafa, M. Q. \& Shahbazi, I. A. (2013). Agriculture value added and income inequality in Pakistan: a time series analysis. http://www.journals.cz. 8(2), 25-33.

Alper, A. E. \& Demiral, M. (2017). Türkiye'nin turizm piyasaları için yakınsama hipotezinin testi: Fourier durağanlık analizi bulguları. Ömer Halisdemir Üniversitesi İktisadi ve İdari Bilimler Fakültesi Dergisi. 10(4), 205-213.

Bashir, A.; Susetyo, D. Suhel. \& Azwardi. (2018). The relationship between economic growth, human capital, and agriculture sector: empirical evidence from Indonesia. International Journal of Food and Agricultural Economics. 6(4). 35-52. 
Becker, R.; Enders, W. \& Lee, J. (2006). A stationary test in the presence of an unknown number of smooth breaks. Journal OfTime Series Analysis. 27(3), 381-409.

Ceylan, R. (2010a). G-7 ülkelerinin yakınsama deneyimi: 1870 - 2006. Süleyman Demirel İktisadi ve İdari Bilimler Fakültesi Dergisi. 15(3), 311-324.

Ceylan, R. (2010b). Yakınsama hipotezi: teorik tartışmalar. Sosyo Ekonomi Dergisi. 48-60.

Ceylan, R. F. \& Özkan, B. (2013). Agricultural value added and economic growth in the European Union accession process. $A$ Mediterranean Journal Of Economics. 4, 62-71.

Cowan, T. (2002). Value-added agricultural enterprises in rural development strategies. Report For Congress, 1-42.

Doğan, A. (2009). Ekonomik gelişme sürecine tarımın katkısı: Türkiye örneği. Süleyman Demirel Üniversitesi İktisadi ve İdari Bilimler Fakültesi Sosyal ve Ekonomik Araştırmalar Dergisi. 9(17), 365 - 392.

Doğan, H. G.; Kan, A. \& Kan, M. (2019). The nexus of agricultural credit and agricultural gross domestic product (gdp) in terms of European Union rural area typology in Turkey. Turkish Journal Of Agriculture - Food Science and Technology. 7(11), 19661971.

Doğan, Z.; Arslan, S. \& Berkman, A. N. (2015). Türkiye'de tarım sektörünün iktisadi gelişimi ve sorunları: tarihsel bir bakış. Niğde Üniversitesi İktisadi ve İdari Bilimler Fakültesi Dergisi. 8(1), $29-41$.

Esenyel. N. M. (2017). Türkiye'de enerji yakınsama hipotezinin sınanması: Yapısal kırılmalı birim kök testi. Social Sciences Research Journal. 6(3), 42-52.

Güriş, B.; Yaşgül, Y. S. \& Tıraşoğlu, M. (2017). E7 ülkelerinde satın alma gücü paritesinin geçerliliğinin doğrusal ve doğrusal olmayan birim kök testleri ile analizi. İstanbul Gelişim Üniversitesi Sosyal Bilimler Dergisi. 4(2), 33-46. 
Harvey, D. I. \& Leybourne, S. J. (2007). Testing for time series linearity. Econometrics Journal. 10, 149-165.

Harvey, D. I.; Leybourne, S. J. \& Xiao, B. (2008). A powerful test for linearity when the order of integration is unknown. Studies In Nonlinear Dynamic \& Econometrics. 12(3), 1-21.

Lu, R. \& Dudensing, R. (2015). What do we mean by value - added agriculture?. A Publication Of The Agricultural \& Applied Economics Association. 30(4), 1-8.

Rassekh, F. (1998). The convergence hypotesis: History, theory and evidence. Open Economics Review, 9, 85-105.

Rivas, G.; Dolores, M., Villaroya, S. \& Isabel. (2017). Testing the convergence hypotesis for OECD countries: a reappraisal. Economics: The Open - Access, Assessment E - Journal. 11(4), 1-22.

Shah, S.; Muhammd, A. H. \& Farooq, R. M. A. (2015). Agricultural export and economic growth: A case study of Pakistan. Public Policy and Administration Research. 5(8), 88-96.

Sollis, R. (2009). A simple unit root test against asymmetric STAR nonlinearity with an application to real exchange rates in NORDİC countries. Economic Modelling, 26, 118-125.

Soyyiğit, S. \& Yavuzaslan, K. (2019). Tarımsal katma değeri etkileyen faktörler üzerine bir inceleme: E7 ülkeleri örneği. Kafkas Üniversitesi İktisadi ve İdari Bilimler Fakültesi Dergisi. 10(19), 403429.

Şimşir, N. C. (2012). An econometric analysis of the relationships between economic growth and agricultural credits for pro-poor growth in Turkey. International Journal Of Social Sciences And Humanity Studies. 4(2), 355-364.

Tekin, İ. (2018). Türkiye'de işsizlik histerisi: Fourier fonksiyonlu durağanlık sınamaları. Dokuz Eylül Üniversitesi İktisadi ve İdari Bilimler Fakültesi Dergisi. 33(1), 97-127. 
Verter, N. \& Becvarova, V. (2016). The impact of agricultural exports on economic growth in Nigeria. Acta Universitatis Agriculturae Et Silviculturae Mendelianae Brunensis. 64(2), 691-700.

Yazgan, Ş.; Ceylan, R. \& Mollavelioğlu, M. Ş. (2018). Seçilmiş NATO ülkelerinde askeri harcamaların yakınsaması: Doğrusal olmayan birim kök testinden kanitlar. Akdeniz Üniversitesi İktisadi ve İdari Bilimler Fakültesi Dergisi. 37, 118-132.

Yılancı, V. \& Tıraşoğlu, M. (2016). Türkiye' nin makroekonomik zaman serilerinin doğrusallığının testi. Çankırı Karatekin Üniversitesi İktisadi ve İdari Bilimler Fakültesi Dergisi. 6(2), 1-16.

Yılancı, V. (2017). Petrol fiyatları ile ekonomik büyüme arasındaki ilişkinin incelenmesi: Fourier yaklaşımı. Ekonometri ve İstatistik Dergisi. 27, 51-67.

https://www.databank.worldbank.org/source/world-developmentindicators [Erişim tarihi: 10 Nisan 2020]. 